\title{
Underground Cemented Backfill, a Design Procedure for an Integrated Mining Waste Management.
}

\author{
KHALDOUN Abdelhadi ${ }^{1}$, OUADIF Latifa ${ }^{1}$, BAHI Lahcen ${ }^{1}$, BABA Khadija ${ }^{1}$. \\ ${ }^{1}$ Mohamed V University, Mohammadia Engineering School, Department of Mineral Engineering, 3GIE Laboratory, \\ Rabat, Morocco.
}

\begin{abstract}
From several case studies around the world, it is well known that the binder represents the major part of backfilling operation cost. Therefore, in the case of Imiter operation, research were mainly focused on the optimization of binder content. To this end, the definition of the physical and chemical properties of the future formula ingredients, specifically: tailings, waste material and hydraulic binder, was necessary. Analytical verifications were conducted to predict the UCB mechanical strength according to the defined underground functions and delivery network. Experimental testing, including: uniaxial compression, Immediate Bearing Index (IBI) and slump test, were then conducted to evaluate the possibility of reaching the required strength with the selected materials. The obtained results show that the tailings and mining wastes can be used as backfilling material with a specific binder content depending on each underground application. The followed approach can be applied for a prefeasibility evaluation for a backfilling facility.
\end{abstract}

Keywords: underground mining, waste management, cemented backfill, design optimization

\section{Introduction}

Based on the case of study of Imiter operation, this paper presents a simplified method for the design procedure of Underground Cemented Backfill (UCB). Unlike conventional cemented backfills, the proposed UCB includes both total mill tailing and crashed waste rock mixed with a specific binder content. The proposed method is an iterative process comprising tree main steps: 1) material characterization, 2) mechanical strength prediction 3) Recipe optimization. This last consist of an iterative process comprising laboratory investigation, full-size testing and in-situ monitoring.

\section{Materials and methods}

\subsection{Waste material characterization}

\subsubsection{Waste dumps material}

Table 1 presents results of conventional laboratory testing for crashed sand and aggregates from the mine waste dumps. These results confirm acceptable characteristics according to Moroccan standards.

Although UCB materials are not at the same requirement level of conventional concrete, this results show the quality of used materials which will eventually improve quality of final product. 
Table 1. Laboratory characterization of crushed rock waste. (Testing standard: NM10.1.27, Morocco)

\begin{tabular}{|c|c|c|c|c|}
\hline Test & $\begin{array}{c}\text { Flatness } \\
\text { Coefficient (\%) }\end{array}$ & $\begin{array}{c}\text { Superficial } \\
\text { Cleanliness (\%) }\end{array}$ & $\begin{array}{c}\text { Los Angeles } \\
\text { Hardness (\%) }\end{array}$ & $\begin{array}{c}\text { Sand Equivalent } \\
(\boldsymbol{\%})\end{array}$ \\
\hline Results & 23 & 0.3 & 15 & 56 \\
\hline Standard & $\leqq 25$ & $\leqq 3$ & $\leqq 30$ & $\underline{\underline{300}}$ \\
\hline
\end{tabular}

\subsubsection{Tailings}

The methylene blue test gives an index value of $\mathbf{3 . 4}$ $\mathbf{g} / \mathbf{K g}$, it indicates a silty medium plasticity material according to GTR* Guide. At least $\mathbf{1 5 \%}$ of the particles in the fill material should be finer than 20 $\boldsymbol{\mu} \mathbf{m}$; if the tailings contain insufficient fines, it may be necessary to add fly ash or additional cement [1]. In this case study, particle size investigation by sedimentation test gives a fines content for about $\mathbf{5 6 \%}$.

Table 2. Results of main heavy elements analysis by ICP method (Analyzing Standard: SW846-6020, USA)

\begin{tabular}{|l|l|l|l|l|l|l|}
\hline Parameter & Antimony & Arsenic & Cadmium & Lead & Manganese & Nickel \\
\hline MDL*(mg/l) & 0.005 & 0.001 & 0.0001 & 0.001 & 0.001 & 0.001 \\
\hline Result $(\mathrm{mg} / \mathrm{l})$ & 0.034 & 0.189 & 0.00064 & 0.014 & 0.223 & 0.167 \\
\hline
\end{tabular}

*Minimum Detection Limit (method limit)

Table 3. Results of total cyanide analysis (Analyzing Standard: APHA-4500-CL, USA)

\begin{tabular}{|c|c|c|c|c|c|}
\hline Parameter & Unit & WHO* & CCME** & USEPA*** & Result \\
\hline Total Cyanide & $\mathrm{mg} / \mathrm{L}$ & 0,070 & 0.200 & 0.200 & 0.022 \\
\hline
\end{tabular}

*World Health Organisation, Directive for Cynaide Concentration in Drinking Wtaer 1996,

**Canadian Council of Ministers of the Environment, Maximum Acceptable Concentration of Cyanide in Drinking Water, 2007

***United States Environmental Protection Agency, Maximum Contaminant Level Goals in Drinking Water, 1997.

\section{$2.2 \quad$ Mining Backfill Design}

In addition to the weight of the backfill, the stress components in a filled stope are also affected by the walls-fill interactions. This allow horizontal stress transfer to the sidewalls due to frictional and/or cohesive interactions. Thus, the vertical pressure at the bottom of filled stope, is less than the weight of overlying fill. This phenomenon is known as the Arching Effect [2, 3].

Uniaxial Compressive Strength (UCS), easily obtained from laboratory testing, is generally used to evaluate UCB stability. Many mine operations still using twodimensional limit equilibrium analyses to determine fill exposure stability with no consideration of the arching effect. These analyses can result in an overestimation of the design UCS [4] which increase the backfilling costs. Analytical methods developed to account for arching phenomenon include mainly the initial Arching Theory and its modifications [5-8] and the 3D Sliding Wedge Failure [9].
Mitchell et al. (1982) proposed an arching model based on wedge limit equilibrium analysis and physical modeling. The Equation 1 describing Mitchell solution was obtained by considering the followings assumptions:

- Stope geometry of a height largely superior to its width $(\mathrm{H}>>\mathrm{B})$,

- Null fill friction angle $(\phi=0)$,

- Fill cohesion equal to that of interface between the fill and the side wall.

$$
\mathrm{UCS}_{\text {destgn }}=\frac{\mathrm{YL} H}{H+\mathrm{L}} \mathrm{FS}
$$

where $\gamma=$ fill bulk unit weight $(\mathrm{kN} / \mathrm{m} 3) ; \mathrm{L}=$ strike length of stope $(\mathrm{m}) ; \mathrm{H}=$ total height of fill $(\mathrm{m}) ; \mathrm{FS}=$ factor of safety.

Despite limitations of the Mitchell et al. (1982) model related to the main above assumptions, this solution has been commonly used in mine backfill design, and has reduced significantly cement consumption compared to 
that required by unconfined-model solutions. Some updates have been proposed by authors to overcome these limitations and develop a more general solution for estimating the required strength of the cemented fill material [10-12].

Unlike the 3D wedge model described above, models developed from the initial aching theory [2] take into consideration the frictional property of the backfill material $(\phi \neq 0)$. Equation 2 and Equation 3 presents a modified two-dimensional solution for vertical and horizontal stress estimating [6].

$$
\begin{array}{r}
\sigma_{\mathrm{vh}}=\frac{\gamma B}{2 K \tan \delta^{\prime}}\left[1-\exp \left(\frac{-2 K H}{\operatorname{Btan} \delta^{\prime}}\right)\right] \\
\sigma_{\mathrm{hh}}=\mathrm{K} \sigma_{\mathrm{vh}}
\end{array}
$$

where $\sigma_{\mathrm{vh}}(\mathrm{KPa})$ and $\sigma_{\mathrm{hh}}(\mathrm{KPa})$, are the vertical and horizontal stresses at depth $\mathrm{H}(\mathrm{m})$, respectively; $\gamma$ $(\mathrm{MN} / \mathrm{m} 3)$ represents the unit weight of the backfill; $\delta^{\prime}$ $\left({ }^{\circ}\right)$ is the effective friction angle between the wall and backfill, generally taken as $2 / 3$ of the backfill frictional angle $\phi_{\text {bf }}^{\prime}\left({ }^{\circ}\right)[13]$.

$\mathrm{K}$ is the ratio of the horizontal stress $\sigma_{\mathrm{hh}}$ to vertical stress $\sigma_{\mathrm{vh}}$. It's a reaction coefficient depending on the horizontal wall movement and material properties. When there is no relative displacement of the walls, the fill is said to be at rest, and the reaction coefficient is usually given by Equation 4 [14].

$$
\mathbf{K}=1-\sin \left(\phi_{\mathrm{bf}}^{r}\right)
$$

The design UCS depends on the underground function of the backfill and stope geometry. In Imiter Mine, typically stopes of $5 \mathrm{~m}$ width and $5 \mathrm{~m}$ height are mined with fill-and-cut instead $20 \mathrm{~m}$ height for sublevel stoping method with a stope length of $30 \mathrm{~m}$. The principal UCB function for cut-and-fill stoping is to give a working platform for next tranches and walls support for the global stability of the mine. With sublevel stoping, UCB allows face freestanding exposure for pillar recovery. UCB ensure also the sill mat function for both method to minimize mining panels interfering and allow undercut mining.

\subsubsection{Pillar recovery}

\section{Design considering the arching effect}

For Imiter case, application of Equation $\mathbf{1}$ and Equation 2 gives respectively a required strength of 480 and $549 \mathrm{kPa}$ with consideration of a fill unit weight of $20 \mathrm{kN} / \mathrm{m} 3$, a minimal fiction angle of $30^{\circ}$ and a typical safety factor of 2.0.

The friction angle of the backfill is an important parameter when evaluating the stability with Equation 2. This parameter can be obtained with laboratory (triaxial, direct shear) or in-situ testing. The friction angle of the studied Imiter backfill is assumed to be greater than $30^{\circ}$ because of the angular shape of the crashed sand and aggregates used at a percentage of approximately $60 \%$ from the total weight of the backfill solid material.

\section{Design with no arching effect}

In case of stope with no arching effect, which can correspond to a backfill with more than two exposed faces, the fill block is subjected to gravity loading similar to a uniaxial compression sample. The design UCS can be estimated by Equation 5 [15], which gives a design UCS of $800 \mathrm{kPa}$ for Imiter case study.

$$
\mathrm{UCS}_{\text {design }}=\left(\mathrm{\gamma}_{\mathrm{f}} \mathrm{H}_{\mathrm{f}}\right) \mathrm{FS}
$$

where $\gamma_{\mathrm{f}}=$ fill bulk unit weight $(\mathrm{kN} / \mathrm{m} 3) ; \mathrm{H}_{\mathrm{f}}=$ total fill height (m); FS = Factor of Safety.

\subsubsection{Working platform}

In cut-and-fill stoping, backfilling is performed with cyclic operations. Each filled tranche serves as a working platform for workers and mining equipment for next level. UCB must so develop sufficient strength (bearing capacity) at the short term to allow operations sequencing. A strength limit of $100 \mathrm{KPa}$ is generally admitted to avoid UCB liquefaction [16] and a bearing capacity of $30 \mathrm{KN}$ for a working platform [17]. The bearing capacity for fresh UCB can be estimated using equations Equation 6, Equation 7 and Equation 8 developed for foundation design in civil engineering:

$$
\begin{array}{r}
q_{\mathrm{f}}=\mathrm{cN}_{\mathrm{s}}+\mathrm{\gamma DN}_{\mathrm{q}}+\frac{1}{2} \mathrm{\gamma BN}_{\mathrm{Y}} \\
\mathrm{N}_{\mathrm{q}}=\mathrm{e}^{(\pi \tan \varphi)} \tan ^{2}\left(45+\frac{\Phi}{2}\right) \\
\mathrm{N}_{\mathrm{c}}=\left(\mathrm{N}_{\mathrm{q}}-1\right) \cot \varphi
\end{array}
$$

Where $\mathrm{c}=$ cohesive strength of fill $(\mathrm{kPa}), \phi=$ intern frictional angle of fill (degree). $\gamma=$ bulk unit weight of the fill $(\mathrm{kN} / \mathrm{m} \mathrm{3}), \mathrm{D}=$ foundation footing depth from surface $(\mathrm{m}), \mathrm{B}=$ foundation breadth $(\mathrm{m}) ; \mathrm{N} \gamma=$ unit weight bearing capacity factor; $\mathrm{N} \mathrm{c}=$ cohesion bearing capacity factor; $\mathrm{Nq}=$ surcharge bearing capacity factor; In case of backfilled stope, the $\mathrm{B}$ dimension is equivalent to the width of tire surface contact on the fill. This can be determined by Equation 9 [16].

$$
\mathbf{B}=\sqrt{\frac{F_{t}}{p}}
$$

Where $F_{t}$ is tire loading force $(k N)$ and $p$ is tire air pressure $\left(\mathrm{kN} / \mathrm{m}^{2}\right)$.

In civil engineering, value of $\mathrm{N} \gamma$ factor can be calculated by Equation 10 [18].

$$
\mathrm{N}_{\mathrm{\gamma}}=\mathbf{2}\left(\mathrm{N}_{\mathrm{Q}}-\mathbf{1}\right) \tan \varphi
$$

Considering that fresh UCB has nil cohesion and an estimated friction angle of $30^{\circ}$, Equation 6 gives a bearing capacity of $100 \mathrm{kN} / \mathrm{m}^{2}$. The limit bearing capacity of $30 \mathrm{kN} / \mathrm{m}^{2}$ giving an adequate working platform [17] is reached with a friction angle of $23^{\circ}$. To evaluate the trafficability of UCB in term of curing 
time, Immediate Bearing Index (IBI) test, also known as Immediate CBR Index, can be used to predict the strength behavior of the fill. Based on IBI results, the

\subsubsection{Sill mat}

To minimize mining panels interfering and improve the global strength of the rock mass, UCB is used as sill mat fill where it ensure a supporting function. However, the main function of the sill mat is to allow underhand cut-and-fill mining. Ideally, the design of a sill mat fill take into consideration the vertical and lateral loading, stope geometry, failure modes, seismic effects, and mechanical properties. It is critical to know the sill mat loading to determine the required strength of the fill. An under-estimation can cause premature failure when the sill mat is exposed by mining extraction. The overestimation implies additional cement which increases the sill mat cost. The vertical loading onto the sill mat can be estimated by the arching theory equations presented in section 2.5. Considering a vertical stope with an infinite backfill thickness, the vertical stress exercised by the overlying backfill on the UCB sill mat can be calculated by Equation11 [19].

$$
\sigma_{v}=\frac{\gamma \mathrm{B}}{2 \mathrm{kntan} \varphi}
$$

Where $\sigma_{\mathrm{v}}(\mathrm{kPa})$ is the vertical stress applied by the overlying backfill on the sill mat, B (m) is the span of the sill mat (or width of the stope), $\gamma(\mathrm{kN} / \mathrm{m} 3)$ and $\phi\left({ }^{\circ}\right)$ are, respectively, the unit weight and friction angle of the overlying backfill, and $\mathrm{K}(-)$ is the lateral earth pressure coefficient in the backfilled stope above the sill mat. As described by Mitchell (1991), four failure modes condition the sill mat stability; the failure can be a result of a flexural, sliding, rotational or caving mechanism. Assuming that there is a good and controlled quality of the contact fill-walls, the flexural failure is more critical than rotational or sliding failure. Flexural failure of the sill mat is mainly related to backfill loading. However, stresses generated by wall convergence can lead to compressive failure if the limit strength of the material is exceeded. Mott (2002) [20] proposed Equation 12 to estimate the limit flexural strength for a fixed sill mat. Flexural failure, referred to as tensile failure, is the most common and requiring the highest strength to prevent failure, as such it is used as the critical design criteria.
UCB ability to be used as working plate-form is evaluated according the IBI standard classification.

$$
\sigma_{\mathrm{t}}=\frac{3}{4}\left(\frac{\mathrm{rL}^{2}}{\mathrm{~d}}\right)
$$

The corresponding factor of safety is given by Equation13; $\sigma_{t}$ is assumed to be $1 / 10^{\text {th }}$ of UCS as suggested by many authors [21].

$$
\mathbf{S F}=\frac{4}{3}\left(\frac{\sigma_{\mathrm{t}} \mathrm{h}}{\mathrm{Y}^{2}}\right)
$$

\subsubsection{Underground delivery}

Generally pumping system is required for underground delivery of UCB. Gravity cannot ensure the fill flow in case of important horizontal mining development.

Transfer pumps should be able to handle a flow rate approximately $20 \%$ greater than the design flow rate for the system (solids and water) [1]. The decreasing in flow rate to the critical sedimentation value directly causes complete filling of the pipe. The UCB flowing is principally related to the consistency and so, the viscosity of the fresh backfill.

Due to the complexity of measuring the viscosity which depends on several factors, the slump cone test, originally developed to monitor the consistency of unhardened concrete, gives an indication of the backfill yield stress. The slump is the measure of the drop of the backfill material when it is released from a standard metallic cone. Determination of the slump provides a way to characterize a material's consistency that can be related to its transportability [22, 23]. For a successful pumping system, the ideal slump height range from 150 $\mathrm{mm}\left(5^{\prime \prime}\right)$ to $300 \mathrm{~mm}\left(12{ }^{\prime \prime}\right)[\mathbf{2 4 ,} \mathbf{2 5}]$.

In term of particle size, the backfill material must also contain at least $15 \%$ by weight passing $20 \mu \mathrm{m}$ for a typical flow and retain sufficient colloidal water to create a non-segregating mixture [26].

\subsection{Recipe optimization}

In order to optimize the backfill mixture for Imiter mine, five recipes were defined with variation of the cement content from 1 to $10 \%$ as presented in Table 4. Mixtures presented in Table $\mathbf{4}$ were reconstituted in laboratory for a volume of $1 \mathrm{~m}^{3}$ and were subjected of the following testing: Uniaxial Compressive Strength (UCS); Immediate Bearing Index (IBI); Slump test.

Table 4. Laboratory UCB formulation

\begin{tabular}{|c|c|c|c|c|c|}
\hline Component $(\mathbf{K g})$ & $\mathbf{R 1}$ & $\mathbf{R 2}$ & $\mathbf{R 3}$ & $\mathbf{R 4}$ & $\mathbf{R 5}$ \\
\hline Agregate & 513 & 513 & 490 & 480 & 460 \\
\hline Sand & 620 & 610 & 580 & 570 & 550 \\
\hline Dry tailings & 513 & 500 & 490 & 490 & 460 \\
\hline Fresh water & 341 & 341 & 341 & 325 & 335 \\
\hline Cement & 22 & 44 & 100 & 140 & 200 \\
\hline Total weight & 2009 & 2008 & 2001 & 2005 & 2005 \\
\hline \% Cement & 1 & 2 & 5 & 7 & 10 \\
\hline
\end{tabular}




\section{Uniaxial Compressive Strength}

UCB samples were crafted as cylindrical specimens of $10 \mathrm{~cm}$ diameter and $20 \mathrm{~cm}$ length. Mechanical strength of the analyzed formulations was evaluated by UCS testing for curing time ranging from 1 to 28 days. The obtained results (Fig. 1) show that UCS values range from 0.14 to $2.44 \mathrm{MPa}$ with an exponential trend from day 1 to day 28 .

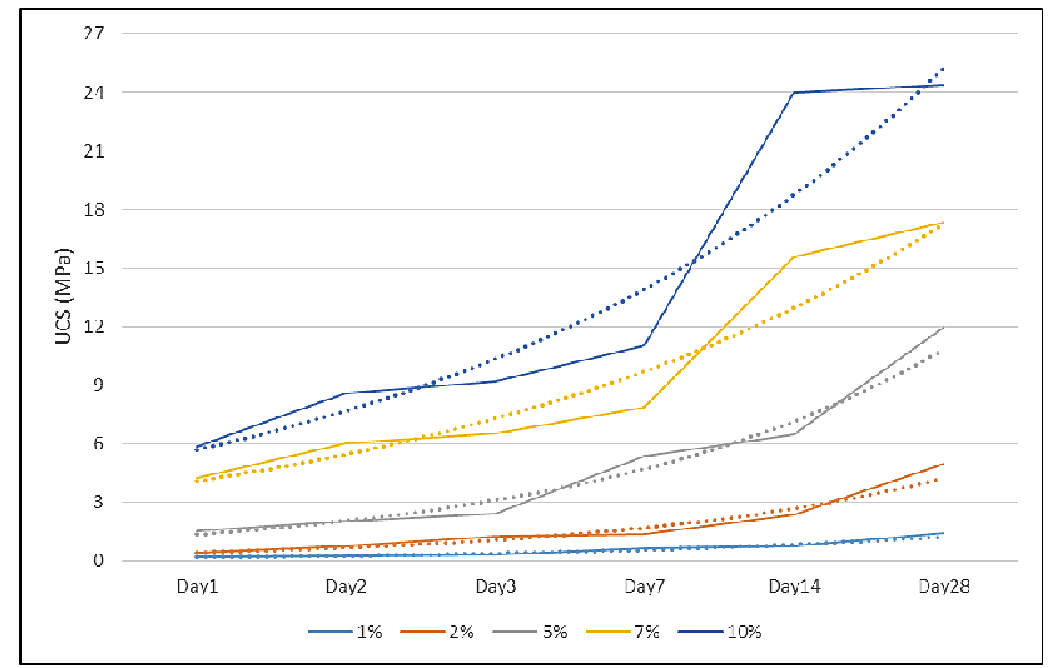

Fig. 1. Trend curve of UCS results from day 1 to day 28

\section{Immediate Bearing Index (IBI)}

The IBI test is generally used to evaluate trafficability of soil foundation during road construction. The test is originally realized on compacted soil simples with the optimum Proctor density. For our case, the test was conducted on crafted cylindrical specimen for the same backfill recipes used for UCS testing. Figure 2 shows that evolution of IBI index for recipe R1, R2, R3 and R4 for a curing age until four days. The objective of this test is to define the curing age after which the backfill can be trafficable by mining equipment.

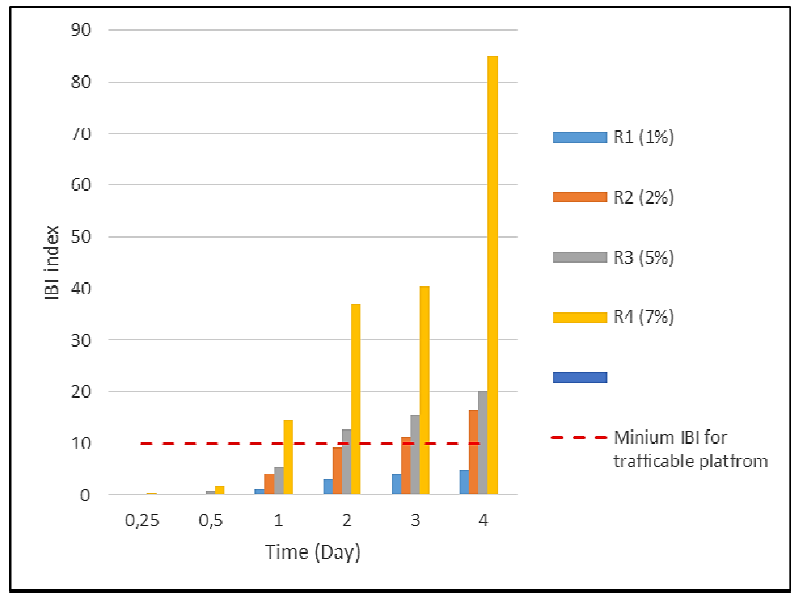

Fig. 2. Evolution of IBI index as function of curing time for recipe R1, R2, R3 and R4.

\section{Discussion}

For the backfill mixture optimization, five recipes were proposed with cement content ranging from 1 to $10 \%$. Mechanical properties were evaluated through Uniaxial Compressive Strength testing. Trafficalbility and pumpbility were respectively analyzed by Immediate Bearing Index and slump test.

According to the UCB design requirements and experimental results, it appears that the adequate proportion of cement in the UCB mixture is situated between 2 and $5 \%$ (recipes R2 and R3) in case of pillar recovery, and $4 \%$ in the case of self-supporting backfill. Except recipe R1, IBI index results show that all backfill recipes allow trafficable platform after four days of curing time. Recipe R3 and R4 can make possible equipment circulation only after a curing age of 2 days. However, if the recipe R3 is chosen as the optimal formulation, tree days of waiting time will be required to adequately upturn the extraction activity in the filled stope. For the concern of underground delivery, the realized cone tests give slumps from 210 to $220 \mathrm{~mm}$, which indicate a fluid slurry easily manipulated by conventional pumping system.

\section{Conclusion}

This paper presented a simplified procedure for mining waste and tailing reutilization through Underground Cemented Backfill. Following this procedure will help operation to develop the adequate backfill mixture based on specificities of each extraction site. The case study of Imiter operation presented in this paper, presented an integrated solution to using both waste rock and tailings as an engineered filling material ensuring different underground functions. Despite the knowing environmental benefits of mining waste reusing, improved understanding of cementitious binding mechanisms will be important in improving and reducing potential heavy element release to the environment. Other important issues also remain to be resolved, including the long term evolving properties of 
the fill material, the seismic impact related to blastinduced vibrations. It must also be noted that the important quantity of available wastes implies evaluation of other reusing solutions, especially in building and large civil works.

\section{Acknowledgements}

The authors would like to thank the SMI mining operation, Morocco, for the support of this work.

\section{References}

1. Hambley D F, Backfill Mining. In: Darling P, editor. Mining Engineering Handbook, 3rd ed. USA, Society for Mining, Metallurgy, and Exploration, pp. 1375-1384 (2011).

2. Marston A. The theory of external loads on closed conduits in the light of latest experiments. Bulletin 96, Iowa Engineering Experiment Station, Ames Iowa (1930).

3. Terzaghi K, Theoretical soil mechanics. New York: John Wiley \& Sons (1943).

4. Stone DMR., The optimization of mix designs for cemented rock fill. In: Glen $\mathrm{H}$ W, editor. MINEFILL'93 - The 5th International Symposium on Mining with Backfill. Johannesburg, South Africa, SAIMM, pp. 249-253 (1993).

5. Winch $\mathrm{C}$, Geotechnical characteristics and stability of paste backfill at BHP Cannington mine. PhD, James Cook University, Townsville, Australia (1999).

6. Aubertin M, Li L, Arnoldi S, Belem T, Bussière B, Benzaazoua M, Simon R., Interaction between backfill and rock mass in narrow stopes. In: Culligan PJ, Einstein HH, Whittle AJ (eds) Soil and rock america, vol 1. Verlag Glückauf Essen (VGE), Essen, pp 1157-1164 (2003).

7. Li L, Aubertin M, Belem T, Formulation of a three dimensional analytical solution to evaluate stress in backfilled vertical narrow openings. Can Geotech J 42: 1705-1717 (2005).

8. Pirapakaran K, Sivakugan N., Arching within Hydraulic Fill Stopes. Geotech Geol Eng 25: 25-35.

9. Mitchell RJ, Olsen RS, Smith JD 1982. Model studies on cemented tailings used in mine backfill. Can Geotech J 19: 14-28 (2007).

10. Zou S, Nadarajah N, Optimizing backfill design for ground support and cost saving. In: Yale D P, editor. The 41 st US symposium on rock mechanics USRMS) Golden: American Rock Mechanics Association, Colorado, USA, p. 7-21 (2006).

11. Li, L., and Aubertin, M. A modified solution to assess the required strength of exposed backfill in mine stopes. Canadian Geotechnical Journal, 49 (8):994-1002 (2012).

12. Li L, Aubertin M, An improved method to assess the required strength of cemented backfill in underground stopes with an open face. Int J Min Sci Technol 24: 549-558 (2014).
13. Becker DE, Moore ID, Canadian Manual of Foundation Engineering. 4th ed. Canada: Canadian Geotechnical Society (2006).

14. Kumar, S, Design of Pile Foundations, in: Braja M. Das. (Ed.) Geotechnical Engineering Handbook, J. Ross Publishing, Floride, pp. 189-258 (2010).

15. Yu T R, Mechanisms of Fill Failure and Fill Strength Requirements. In: Canadian Association of Rock Mechanics, editor. The 6th Canadian Rock Mechanics Symposium, Sudbury, Canada, pp. 1-6 (1992).

16. Hassani F, Bois D, Economic and technical feasibility for backfill design in Quebec underground mines Final report 1/2, CanadaQuebec Mineral Development Agreement, Research \& Development in Quebec Mines Contract no EADM 1989-1992, File no 71226002 (1992).

17. Craig RF, Craig's Soil Mechanics. In: Craig RF, editor. Bearing capacity. $7^{\text {th }}$ ed. London, Spon Press, Taylor \& Francis, pp. 294-295 (2004).

18. European Committee for Standardization, Eurocode 7, Geotechnical Design - Part 1: General Rules, Brussels: European Committee for Standardization (2004).

19. Mitchell R J, Sill mat evaluation using centrifuge models, Mining Science and Technology 13: 301313 (1991).

20. Mott, R, Applied strength of materials. Ontario: Prentice Hall (2002).

21. Regal, X., Thèse de Doctorat, Caractérisation du comportement en traction du béton sous fortes sollicitations: essais de flexion trois points aux barres de Hopkinson. Autre. Universitée d'Orléans (2016).

22. Clark CC, Vickery JD, Backer RR, Transport of total tailings paste backfill: results of full-scale pipe test loop pumping tests, report of investigation RI 9573. Washington, Spokane: National Institute for Occupational Safety and Health (1993).

23. Belem T, Benzaazoua M, An overview on the use of paste backfill technology as a ground support method in cut-and-fill mines. In: The 5th Int Symp on Ground support in Mining and Underground Construction: Villaescusa E,Potvin Y. editors., Perth, Australia, pp. 637 - 650 (2004).

24. Landriault D.A., Verburg R., Cincilla W. and Welch D, Paste technology for underground backfill and surface tailings disposal applications. Short course

25. Benzaazoua M, Ouellet J, Servant, S, Newman P, Verburg R, Cementitious mine backfill with high sulfur content: physical, chemical and mineralogical characterization. Cem Concr Res 29: 719-725 (1999).

26. Hassani F., Archibald, J, Mine backfill Hand Book. Montreal: Canadian Institute of Mining, Metallurgy and Petroleum (1998). 